\title{
Particle engineering of fenofibrate for advanced drug delivery system
}

\author{
Ramakant Joshi ${ }^{1 *} \mathbb{D}$, Srajan Raje ${ }^{2}$, Wasim Akram ${ }^{1}$ and Navneet Garud ${ }^{1}$
}

\begin{abstract}
Background: The goal of the current investigation was to formulate, evaluate co-crystal, and further design of solid unit dosage form of antihyperlipidemic BCS class II drug fenofibrate (FNO). Co-crystals composed of a structurally homogeneous crystalline material that contains two or more components in a definite stoichiometric amount helps in increasing yield, the capability to regulator polymorph fabrication, enhanced invention crystallinity. Ball milling method is used for co-crystal formulation, optimized via $3^{2}$ full factorial design and characterized by saturation solubility, particle size analysis, Fourier transform infrared spectroscopy (FT-IR) study analysis, powder X-ray diffraction (PXRD) study analysis, surface morphology by scanning electron microscopy (SEM) study, flow properties, and ex vivo intestinal permeation study via non-everted rat intestinal sac model. Furthermore, optimized batch compressed into tablets is evaluated for disintegration time, hardness, friability, in vitro drug release study and stability study.

Results: It demonstrated that Co-crystal formulation FNOCC7 shows higher saturation solubility $0.3874 \pm 2.82 \mathrm{~g} / \mathrm{ml}$ with less particle size $221.231 \pm 0.456 \mathrm{~nm}$, FT-IR spectra confirmed significant structural alterations in the formulation indicating the hetero-molecular interaction, the presence of hydrogen bonding had occurred in the cocrystals, PXRD spectra of formulation determined by the increase in the crystalline nature. FNO co-crystals show flux $(F)$ and permeability coefficient $\left(P_{\text {app }}\right) 0.322 \pm 0.068 \mu \mathrm{g} / \mathrm{min}, 5.38 \pm 0.093 \mathrm{~cm} / \mathrm{min}$ respectively increased compared to the pure drug makes in an enhancement of solubility as well as the bioavailability of BCS class II drug.

Conclusions: The solubility and dissolution percentage of FNO can be improved by the utilization of Co-crystal of FNO with PEG 4000. The solubilization impact of PEG 4000 might be contributed because of the decrease of molecule conglomeration of the drug presence of crystallinity, expanded wettability, and dispersibility; pharmaceutical co-crystals speak to a beneficial class of crystal form with regard of pharmaceuticals.
\end{abstract}

Keywords: Crystallization, Co-crystal, Antihyperlipidemic, Solid dispersion, permeability, BCS class II

\section{Background}

Fenofibrate (FNO) stayed in a biopharmaceutics classification system in class II hypolipidemic lipophilic compound by low solubility and great permeability, has high lipophilicity ( $\log \mathrm{P}=5.24$ ) (Fig. 1 ) [1-3]. The pharmacological activity of fenofibric acid, an active metabolite, produces reductions in total cholesterol concentration in plasma, total triglycerides in patients. The bioavailability of Fenofibrate is exclusively based on the rate of dissolution in the gastrointestinal tract. Hence, modifications should be demanded in dissolution study of fenofibrate

\footnotetext{
* Correspondence: joshiram78@gmail.com

${ }^{1}$ School of Studies in Pharmaceutical Sciences, Jiwaji University, Gwalior (M.P)-474011, India

Full list of author information is available at the end of the article
}

dosage forms as it binds its absorption from the gastrointestinal tract [4].

High dose size is required for poorly water-soluble drugs in demand to attain to reach its plasma concentration at a therapeutic level. Oral bioavailability and dose decrease are achieved by the means of improvement in the extent and rate of dissolution. In the field of particle engineering, attempts are undertaken to improve solubility, micrometric, and compression properties, and obtaining suitable polymorphs is one of the key factors for enhancement of the dissolution rate of poorly soluble drugs. Some physical modifications like reduction in particle size and generation of amorphous states enhance the surface area, solubility, and wettability of the powder particles [5-7]. Several studies make sure 


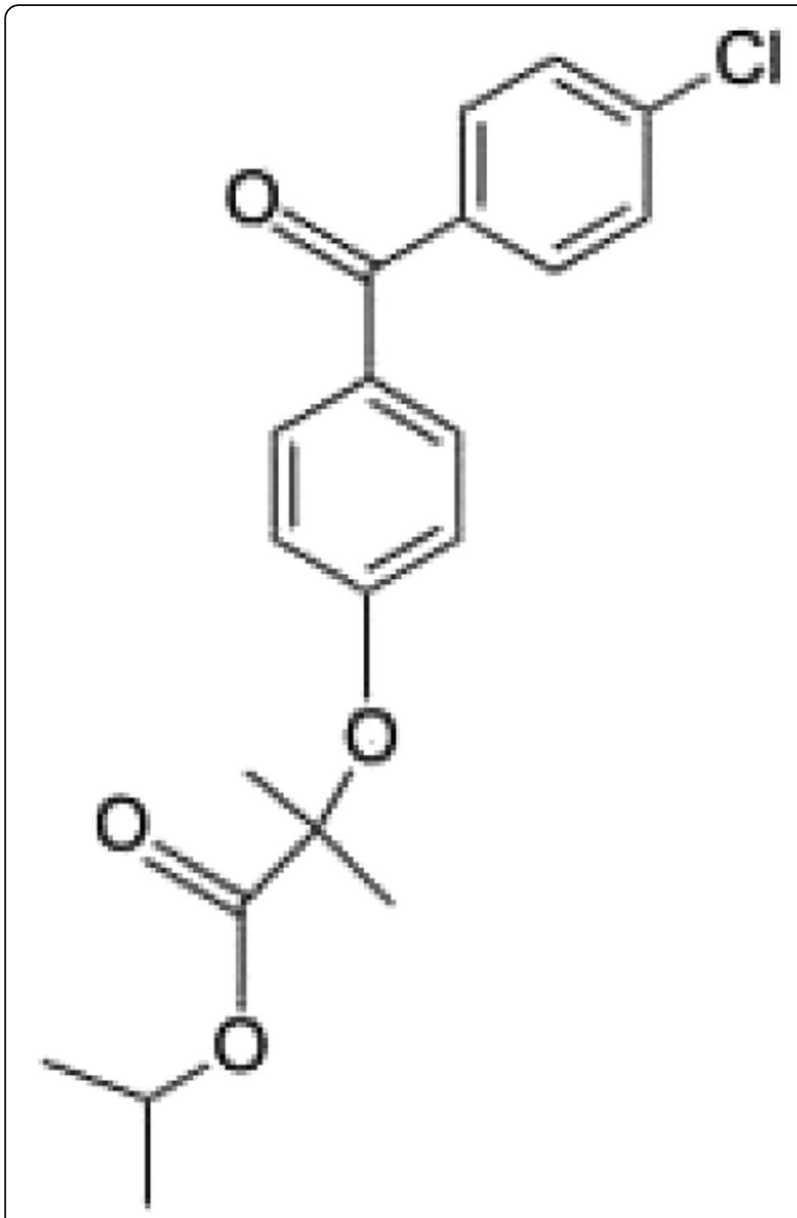

Fig. 1 Compound structure of Fenofibrate

reported to upturn the bioavailability of the fenofibrate orally by using micronization [8], co-grinding and spraydrying [9], the effect of the role of surfactant and $\mathrm{pH}$ [10], nanosuspensions, and SLN [11]. Micronization process increased the bioavailability of drugs, e.g., by jet or ball milling has been fine approved, e.g., danazol [7], progesterone [12], and digoxin [13]. Ball mill method is widely used to reduce the particle size up to nanometer $[10,14]$. Yet, the use of surfactants is a rational methodology, which if executed properly can approximate the GI fluid condition.

Co-crystal technology by ball milling is another evolving approach for the delivery of insoluble drugs. The modification in the physicochemical properties of a drug substance by complexation is highly required for the rate of dissolution, bioavailability, stability, and processing consideration [12, 13, 15, 16]. The model for the development of the co-crystal formulation here was by cogrinding ball mill technique including polyethylene glycol 4000 (PEG 4000) and subsequently preparing solid dosage form. Further, they were evaluated with respect to their Fourier transform infrared spectroscopy (FT-IR), powder X-ray diffraction (PXRD) study analysis, scanning electron microscopy (SEM) study, and in vitro drug release. In vitro dissolution studies of the fenofibrate cocrystals and solid dosage, formulations were performed and compared with commercial fenofibrate products from the market formulation fenoglide.

\section{Methods}

Materials

Fenofibrate (FNO) was procured by way of a gift sample from Abbot Healthcare Ltd. (Goa, India). Polyethylene glycol 4000 (PEG 4000), Lactose was purchased from Merck chemicals, Pvt. Ltd. (Mumbai, India). Sodium starch glycolate, magnesium stearate, polyvinyl pyrrolidone (PVP), and isopropyl alcohol was obtained from Sigma Aldrich (Kolkata, India) and the rest of the chemicals that were used of analytical grade.

\section{Preparation of co-crystal}

The co-crystal process was carried out in a ball mill by maintaining $70 \%$ of its critical velocity using the various size of balls and different time intervals (RPM). A homogenous powder mixture of a weighed PEG 4000 (400 mg) along with FNO (500 mg) was formed in the vessel (Pan) for $30 \mathrm{~min}$ at $100 \mathrm{rpm}$. A $25 \mathrm{ml}$ of stainless steel milling jar contains an oscillatory ball mill having three $9 \mathrm{~mm}$ stainless steel balls are used for FNO with PEG 4000 respectively. At a specified period, i.e., $1 \mathrm{~min}$ to 30 min milling was carried out. By changing the number of balls and time period, nine batches of co-crystals were prepared. The details of each are mentioned in Table 4.

\section{Effect of response variables ( $3^{2}$ factorial designs)}

The aim of the factorial design $\left(3^{2}=2\right.$ variables at 3 levels) was to decide the stages of the three independent variables (Table 1) of balls and time which yield cocrystal with least particle size and more saturation solubility.

\section{Characterization of co-crystals Saturation solubility and particle size}

The determination of saturation solubility performed by dissolving an identified surplus quantity of drug in distilled water, phosphate buffer, ethanol, methanol, isopropyl alcohol, and acetone. The suspensions were magnetically stirred at $20 \mathrm{rev} / \mathrm{min}$ for $48 \mathrm{~h}$ temperature ranges $38 \pm 0.5{ }^{\circ} \mathrm{C}$. Afterwards, at the end withdrawal of

Table 1 Translation of coded labels into the actual unit

\begin{tabular}{llll}
\hline Variable & Coded (level) $=+1$ & level $=0$ & Uncoded $($ level $)=-1$ \\
\hline$X_{1}$ (No. of balls) & 9 & 6 & 3 \\
$X_{2}$ (Time) (Min) & 90 & 60 & 30 \\
\hline
\end{tabular}


samples was done and a membrane filter of $0.45 \mathrm{~mm}$ is utilized for filtration. The resultant filtrates were properly diluted and analysis is done by employing a UVvisible spectrophotometer (Jasco V-500, Japan) at 263 $\mathrm{nm}$. The find out results are shown in triplicate quantities and also their means were stated.

The laser light diffraction technique is used for particle size determination. The apparatus comprised of a Malvern Mastersizer 2000 (Malvern Instruments, Malvern, UK) through assessment of facts by Malvern software version 5.2.

\section{$F T-I R$}

To explore the potential chemical interfaces amongst the drug and the co-former, FT-IR spectral study analysis was done on the Fourier transform infrared spectroscopy (FT-IR) Spectrophotometer (JASCO FT-IR8400 Tokyo, Japan); various samples were mixed with $\mathrm{KBr}$ and creased to create pellets by means $150 \mathrm{~kg} / \mathrm{cm}^{2}$ pressure. FT-IR spectra of PEG 4000, pure FNO and FNO co-crystal were scanned in the $4000-400 \mathrm{~cm}^{-1}$ range.

\section{PXRD}

The powder X-ray diffraction (PXRD) arrangements of pure FNO, pure FNO after ball milling and FNO Cocrystal noted down by means of an X-ray diffractometer (PW 1729. Philips, Netherland), using Copper as an anode material and crystal graphite monochromatic worked on $30 \mathrm{kV}$ voltage apply and $30 \mathrm{~mA}$ of current. Upon $\mathrm{Cu}-\mathrm{K} \alpha$ radiation, samples were exposed over $2 \theta$ angles from 2 to $50^{\circ}$ range. The range and the graphing speed were $5 \times 103 \mathrm{CPS}$ and $10 \mathrm{~mm} /{ }^{\circ} 2 \theta$, respectively.

\section{SEM}

Scanning electron microscopy (SEM) study was done to evaluate co-crystal morphologically. Pure drug FNO and co-crystal were coated with a thin gold-palladium layers by Sputter coater unit (VG-Microtech, UK) and the superficial geography was investigated with a scanning electron microscope (SEM Jeol JSM 6360, Japan) worked at $10 \mathrm{kV}$ of acceleration voltage.

\section{Micromeritic properties}

The flow properties were categorized in expressions of the angle of repose $(\theta)$, Carr's index and Hausner ratio. The angle of repose $(\theta)$ was determined by the procedure in which the handled drug samples were passed from the walls of a funnel that was secure at a place such that hard surface is $2.0 \mathrm{~cm}$ below from the lower tip of the funnel. The co-crystal was passed till period the lower tip of the funnel is touched to the upper tip of the pile surface. The standard value for the angle of repose is given (Table 2).
Table $\mathbf{2}$ The standard value of Angle of repose

\begin{tabular}{ll}
\hline Angle of repose & Flow properties \\
\hline$<25$ & Excellent \\
$25-30$ & Good \\
$30-40$ & passable \\
$>40$ & poor \\
\hline
\end{tabular}

The angle of repose $(\theta)$ calculated using Eq. (1) [17].

$$
\operatorname{Tan} \theta=\mathrm{h} / \mathrm{r}
$$

Where $h=$ height of pile and $r=$ radius of the pile

In a graduated cylinder, an accurately weighed quantity of powder blend was carefully discharged and initial volume was noted down. Afterwards, this was closed with the cover fixed on tap densitometer for 100 tapping and final volume was noted down. This procedure was followed three times. From these readings bulk density (BD), tapped density (TD) are calculated. The standard value for Carr's index is given (Table 3).

Carr's index and Hausner ratio were calculated using Eqs. (2) and (3) [18].

$$
\begin{aligned}
& \text { Carr's Index }=[(\mathrm{TD}-\mathrm{BD}) / \mathrm{TD}] \times 100 \\
& \text { Hausnerratio }=(T D) /(B D)
\end{aligned}
$$

\section{Ex-vivo intestinal absorption study \\ Animals}

About 210-240 g of weight healthy Wistar male rats, were procured from Shree farm, Neemgaon, Bhandara, Nagpur, Maharashtra, India. The rats were kept in polypropylene cages under controlled environmental conditions $\left(24 \pm 1{ }^{\circ} \mathrm{C}, 50 \pm 2 \% \mathrm{RH}\right)$, maintained at 12:12-h light/dark cycle with free access to standard laboratory diet and water. The animals fasted, then again delivered free access to water, medium-term earlier at the beginning of the test.

\section{Non-everted rat intestinal sac model}

The non-everted rat intestinal sac tests were completely dependent on the strategy depicted. The rats were anesthetized by ether inward breath after medium-term starving. And the pain response lost was checked. A cut is made on rat abdomen in middle ranging $4-5 \mathrm{~cm}$, separate out the small intestine and taken for a wash by

Table 3 The standard value of Carr's Index

\begin{tabular}{ll}
\hline Carr's Index & Flow ability \\
\hline $5-10$ & Excellent \\
$12-16$ & Good \\
$23-35$ & Poor \\
$>40$ & Very poor \\
\hline
\end{tabular}


Table 4 Effect of No. of balls \& time on Saturation solubility and particle size distribution of co-crystal $(n=3$, mean \pm SD)

\begin{tabular}{lllll}
\hline Batch No./ Runs & X1 (No. of balls) (...) & X2 (Time) (min.) & Saturation solubility $(\mathrm{g} / \mathrm{ml})\left(\mathrm{Y}_{1}\right)$ & Particle size $(\mathrm{nm}) \pm \mathrm{S} . \mathrm{D}\left(\mathrm{Y}_{2}\right)$ \\
\hline FNOCC1 & $(+1) 9$ & $30(-1)$ & $0.0603 \pm 0.02$ & $1342.0 \pm 0.402$ \\
FNOCC2 & $(-1) 3$ & $90(+1)$ & $0.1034 \pm 0.07$ & $721.329 \pm 0.41$ \\
FNOCC3 & $(-1) 3$ & $90(0)$ & $0.1969 \pm 0.08$ & $453.459 \pm 0.23$ \\
FNOCC4 & $90(+1)$ & $0.0816 \pm 0.02$ & $450.127 \pm 0.62$ \\
FNOCC5 & $60(0)$ & $0.0703 \pm 0.01$ & $443.189 \pm 0.603$ \\
FNOCC6 & $(0$ & $90(+1)$ & $0.1142 \pm 0.05$ & $974.665 \pm 0.512$ \\
FNOCC7 & $(+1) 9$ & $30(-1)$ & $0.3874 \pm 0.32$ & $221.231 \pm 0.456$ \\
FNOCC8 & $(+1) 9$ & $30(-1)$ & $0.1600 \pm 0.04$ & $1371.818 \pm 0.510$ \\
FNOCC9 & $(-1) 3$ & $60(0)$ & $0.1206 \pm 0.03$ & $1095.870 \pm 0.462$ \\
\hline
\end{tabular}

super cold regular oxygenated Krebs Ringer PBS solution of $\mathrm{pH} 7.4$ employing a syringe furnished by sharp end. Then, lower end of ileum and the upper end of the duodenum were detached out into $10 \pm 0.2 \mathrm{~cm}$ long sacs taking a width of $0.5 \mathrm{~cm}$. Every single sac

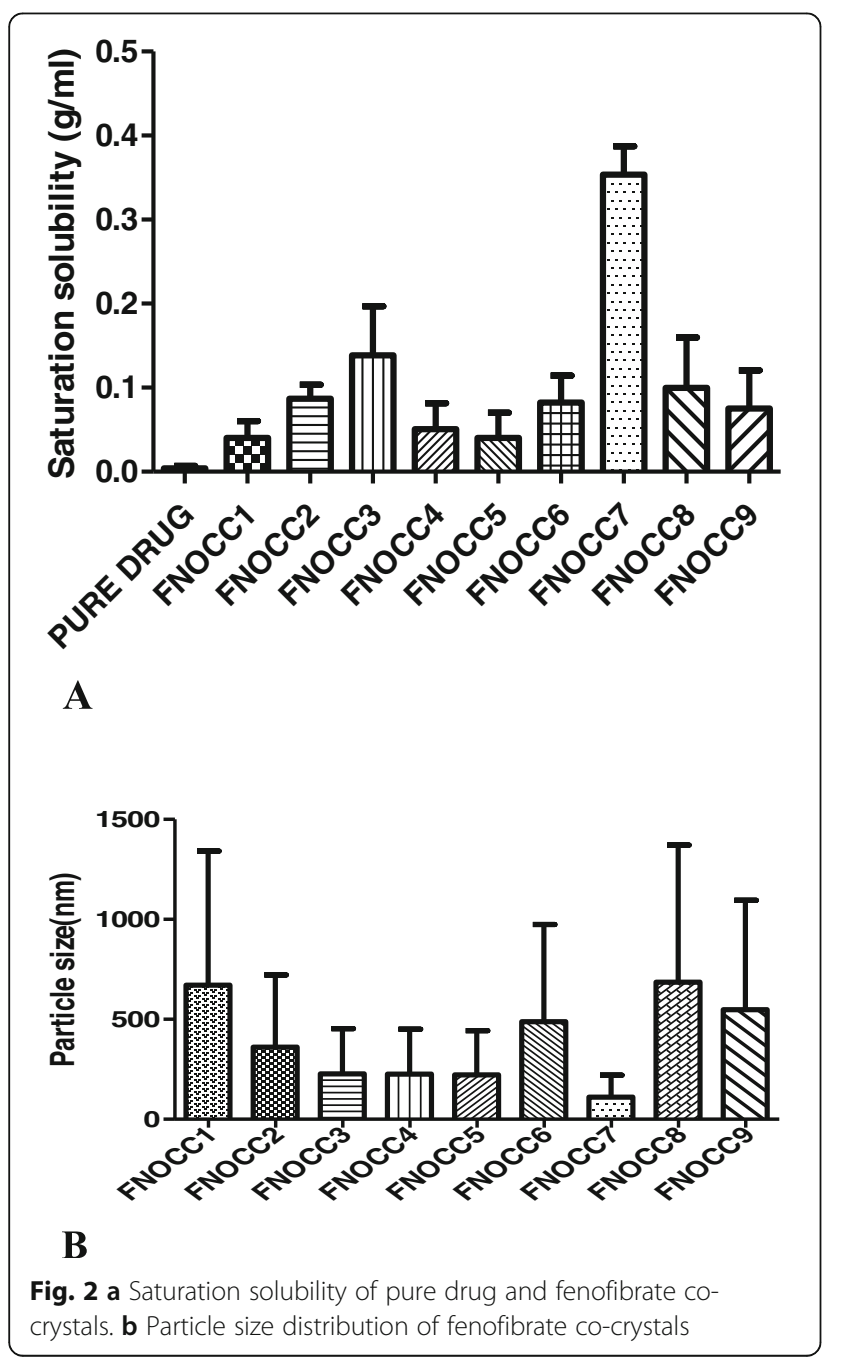

was secured at the individual end, occupied with $1 \mathrm{ml}$ of a suspension of simulated intestinal fluid in which respective drug and processed drug co-crystal is uniformly dispersed $(1 \mathrm{mg} / \mathrm{ml})$ via a blunted pointer in the mucosal partition and was fixed by securing another end [19].

Every non-everted rat intestinal sac was set in a 100 $\mathrm{ml}$ glass beaker holding $90 \mathrm{ml}$ fusion of Krebs Ringer phosphate buffer saline solution $\mathrm{pH} 7.4$ and isopropyl alcohol $(8: 3 \mathrm{v} / \mathrm{v})$ preserved at $38{ }^{\circ} \mathrm{C}$ in a shaky water bath working at $50 \mathrm{rpm}$ and always circulated air through by oxygen $(10-16$ bubble/min) by lab aerator. At times interval, test samples were taken from outdoor of sac (serosal partition) meant for $4 \mathrm{~h}$ and supplanted through new fresh medium each time. Afterwards, filtration is done by Whatman filter paper No. 41 (Whatman, Middlesex, UK), the concentration of FNO found out using UV-visible spectrophotometer $263 \mathrm{~nm}$.

\section{Preparation of solid unit dosage form}

The optimized batch of FNO co-crystal with optimum parameters was prepared in solid unit dosage form using different excipients and co former, sodium starch glycolate, lactose, and magnesium stearate, polyvinyl pyrrolidone. Finishing preparations were delivered from a 16 mesh screen and were directly compressed by 10 punch position tablet machine, via 8 $\mathrm{mm}$ and $11 \mathrm{~mm}$ diameter across round punches with level countenances. The machine setting was in tune to produce tablets of $500 \mathrm{mg}$ weight with a hardness of about $5.5 \pm 0.25 \mathrm{~kg} / \mathrm{cm}^{2}$. Compressed tablets every one comprising of $500 \mathrm{mg}$ of FNO was set up by direct pressure strategy utilizing starch curved in punches as a specifically compressible vehicle. Every one of the ingredients essential according to the formulations was mixed in a sealed polyethylene bag. The mixtures were compressed into tablet pressing machine (Bimix Machinery Co. Pvt. Ltd) to a 


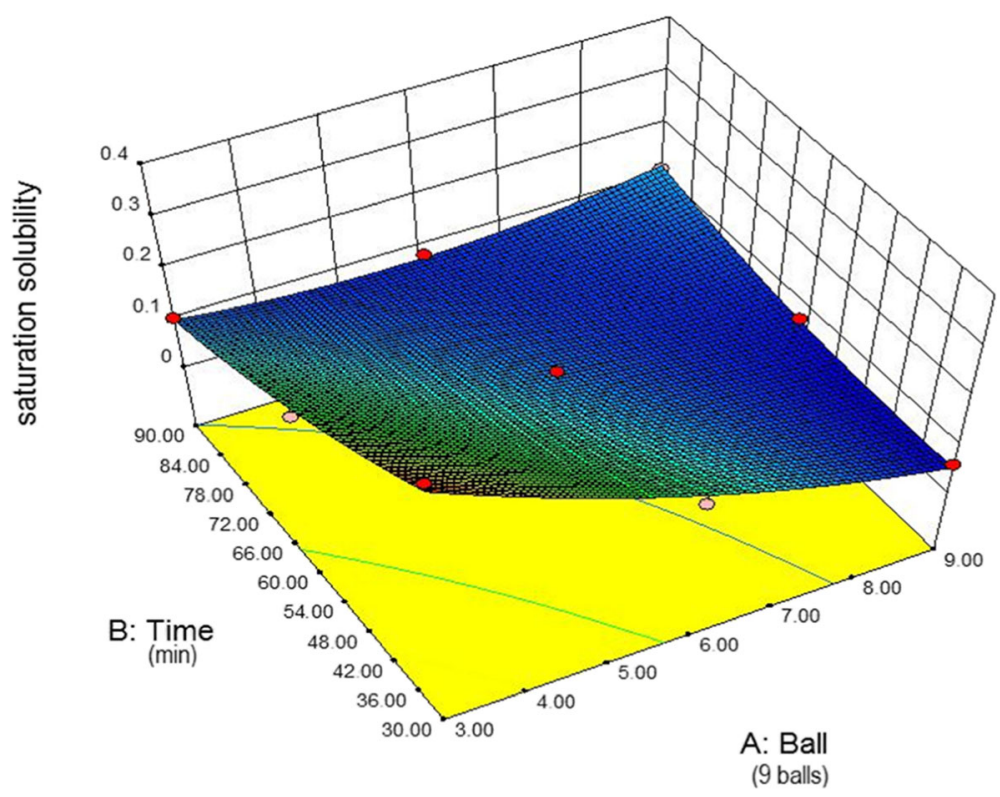

Fig. 3 Response surface curve showing effect of number of balls and time on Saturation Solubility

hardness of $5.5 \pm 0.25 \mathrm{~kg} / \mathrm{cm}^{2}$ using $9 \mathrm{~mm}$ concave punches.

\section{Assessment of solid unit dosage form}

Hardness The hardness of the tablet was dignified using Monsanto hardness tester by placing the tablet between the anvils and measured the force required to break the tablet.

Friability Ten tablets from each batch were correctly weighed and positioned in the friability test apparatus (Roche friabilator). Apparatus was operated at $100 \mathrm{rpm}$ for $4 \mathrm{~min}$. The tablets were taken out after 100 rotations,

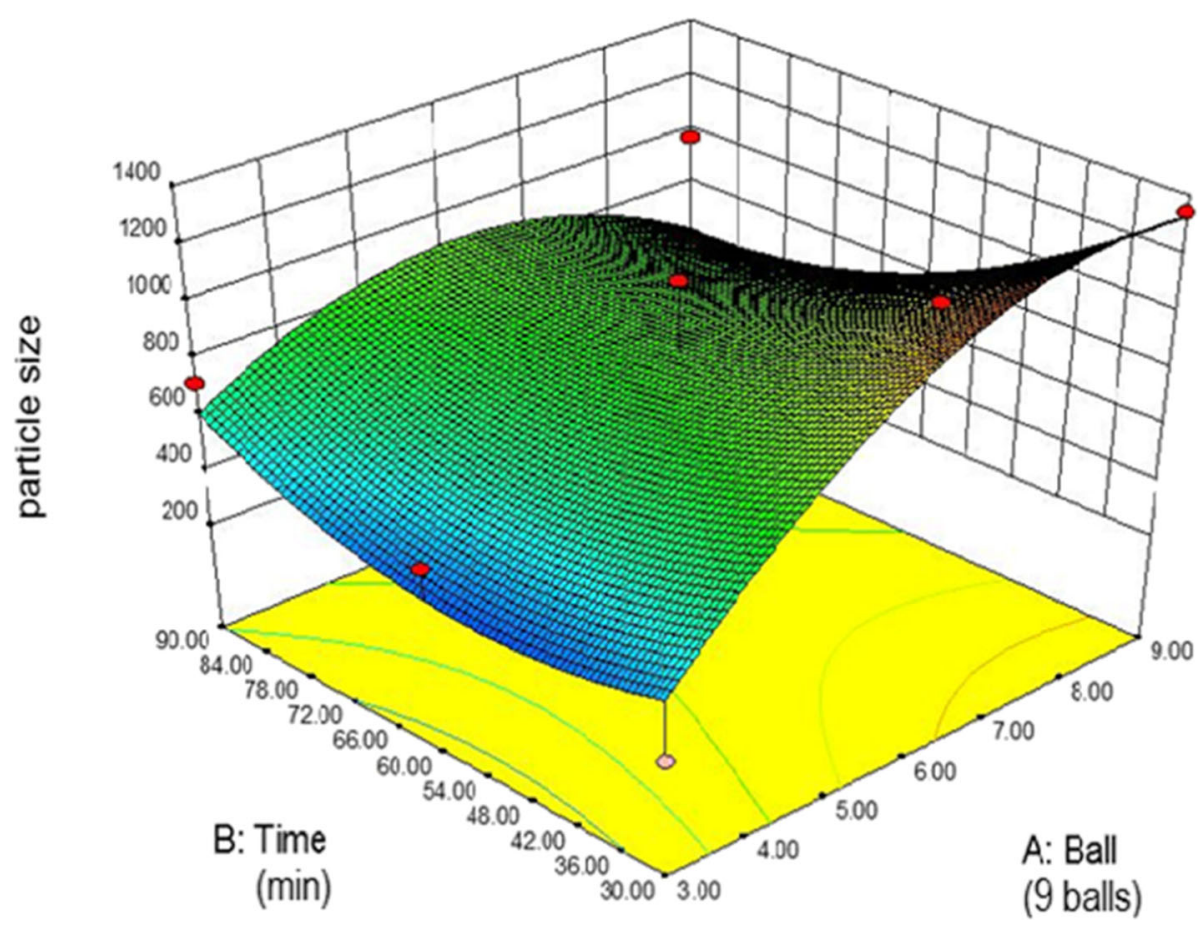

Fig. 4 Response surface curve showing effect of number of balls and time on Particle Size 
dedusted, and reweighed. The friability was calculated as the percentage weight loss by following formulae given below. The $\%$ friability of formulation is shown (Table 8 ) [20].

$$
\% \text { Friability }=\left(\mathrm{W}_{\mathrm{o}}-\mathrm{W}\right) 100 / \mathrm{W}
$$

Where $W_{\mathrm{o}}=$ initial weight of the tablets before testing $W=$ final weight of the tablets after testing

Disintegration test Disintegration test is performed by the USP method (Lab India tablet disintegration test machine model: DT 1000) in which 6 glass tubes, 3 in. long, top open and hold on the $10 \mathrm{in}$. the screen at the lowest end of the basket rack assembly. About $900 \mathrm{ml}$ of PBS $\mathrm{pH} 7.4$ at $37 \pm 2{ }^{\circ} \mathrm{C}$ is taken at basket rack and 1 tablet in every tube is placed. When the tablet is completely disintegrated the disintegration time is noted down.

In vitro dissolution study The paddle type dissolution test apparatus (USP type II) is used for in vitro dissolution study. In that tablet containing $500 \mathrm{mg}$ of FNO and phosphate buffer, $\mathrm{pH} 7.4$ was used as the dissolution media with temperature sustained at $37.0 \pm 0.5^{\circ} \mathrm{C}$ at $100 \mathrm{rpm}$. The volume of sample $(1 \mathrm{ml})$ was withdrawn at $(0,5,15,30,45,60,120 \mathrm{~min})$ interval, passed through Whatman filter paper (No. 41) diluted properly for cumulative drug release using UV-visible spectrophotometer at $263 \mathrm{~nm}$.

Stability study A stability study for processed crystals was accomplished by storing it in closed glass vials at ambient temperature and under accelerated conditions of $40 \pm 2{ }^{\circ} \mathrm{C} / 75 \pm 5 \%$ relative humidity (RH) for up to 3 months as per ICH guidelines.

\section{Results}

Saturation solubility and particle size

The aim of the factorial design $\left(3^{2}=2\right.$ variables at 3 levels) was to conclude the levels of the three independent variables (Table 4) of balls and time which yield co-

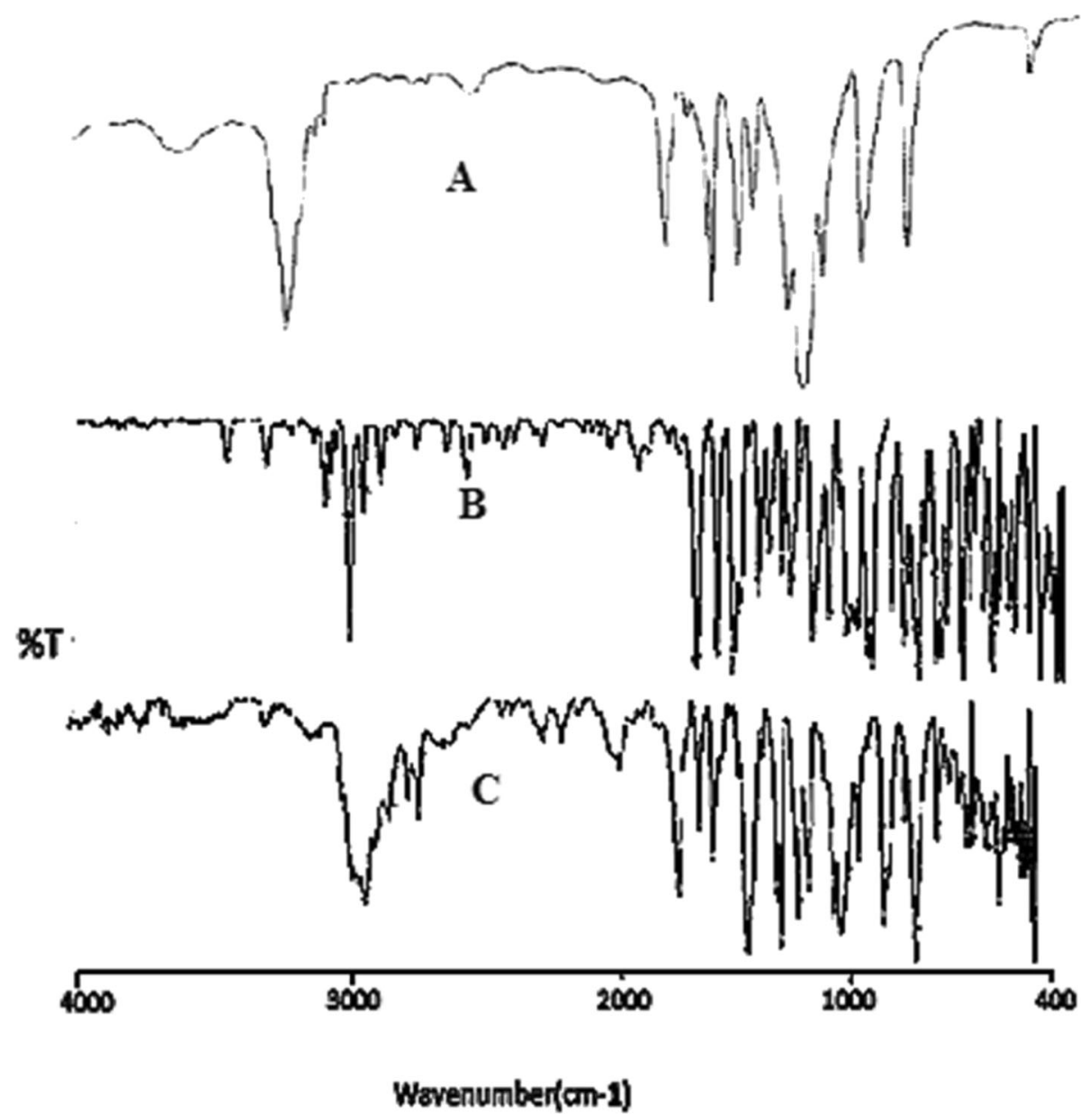

Fig. 5 FT-IR spectra of (a) PEG 4000 (b) Pure Fenofibrate (c) Fenofibrate Co-crystal 


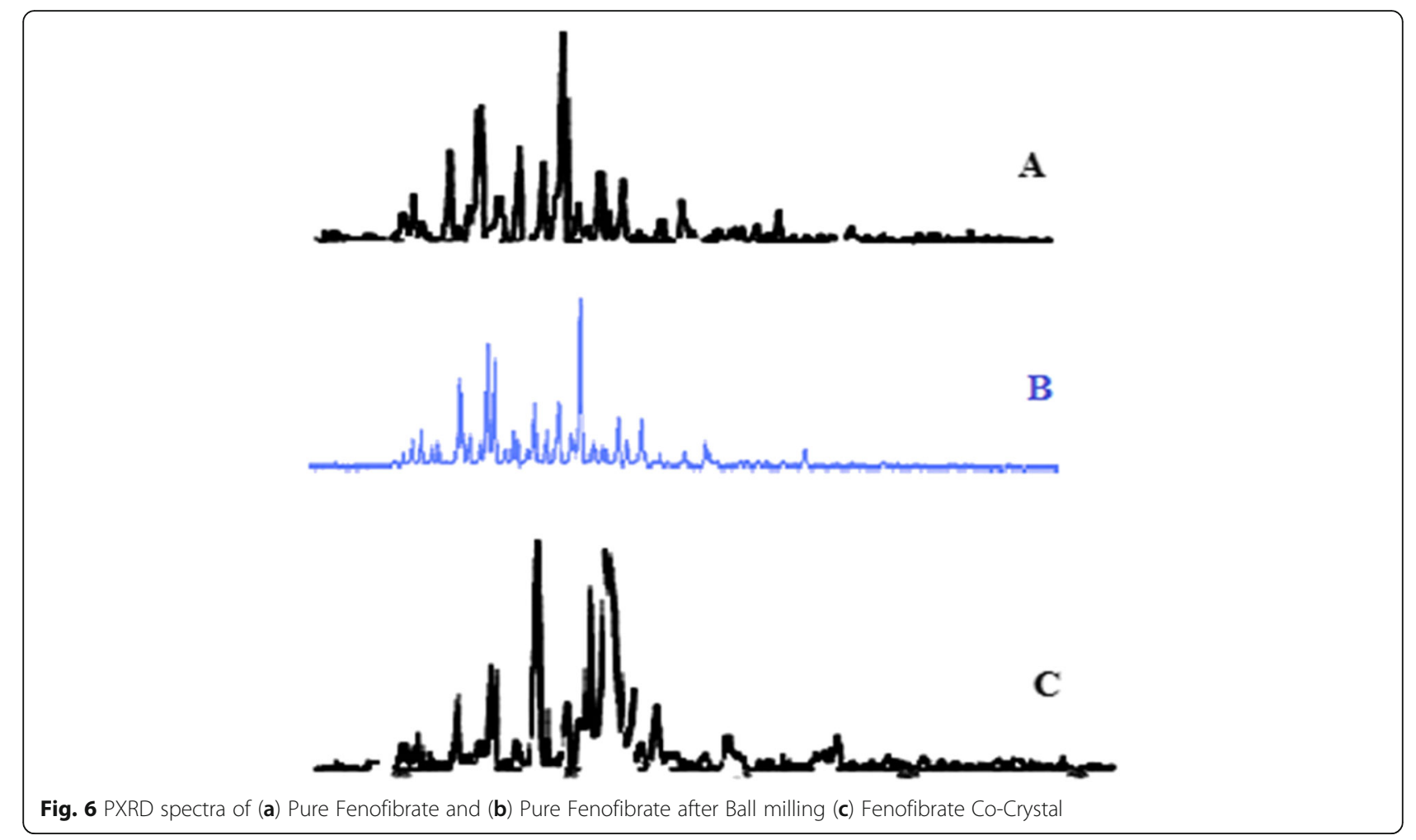

crystal with minimum particle size and maximum saturation solubility (Fig. 2a, b).

\section{Effect on saturation solubility}

$$
\begin{aligned}
\mathrm{Y}_{1}= & 0.11-0.74 \mathrm{X}_{1}-0.051 \mathrm{X}_{2}+0.084 \mathrm{X}_{1} \mathrm{X}_{2} \\
& +0.035 \mathrm{X}_{1}^{2}+0.022 \mathrm{X}_{2}^{2}
\end{aligned}
$$

Values of correlation coefficient indicate a fair fit $\left(R^{2}=\right.$ 0.5701). The impact of process parameters, i.e., a number of balls and time are studied in equation (5). Particle size denotes a negative influence for $X_{1}$ (no. of balls) and
$X_{2}$ (time) where a negative influence on saturation solubility was observed that is supported by the response surface plot (Fig. 3).

Effect on particle size

$$
\begin{aligned}
\mathrm{Y}_{2} & =850.8+227.4 \mathrm{X}_{1}-131.5 \mathrm{X}_{2}-276.9 \mathrm{X}_{1} \mathrm{X}_{2} \\
& -279.9 \mathrm{X}_{1}{ }^{2}+182.7 \mathrm{X}_{2}{ }^{2}
\end{aligned}
$$

Values of correlation coefficient indicate a fair fit $\left(R^{2}=\right.$ 0.9847). Response surface model graph (Fig. 4) and equation (6) depicts the impact of a number of balls $\left(X_{1}\right)$
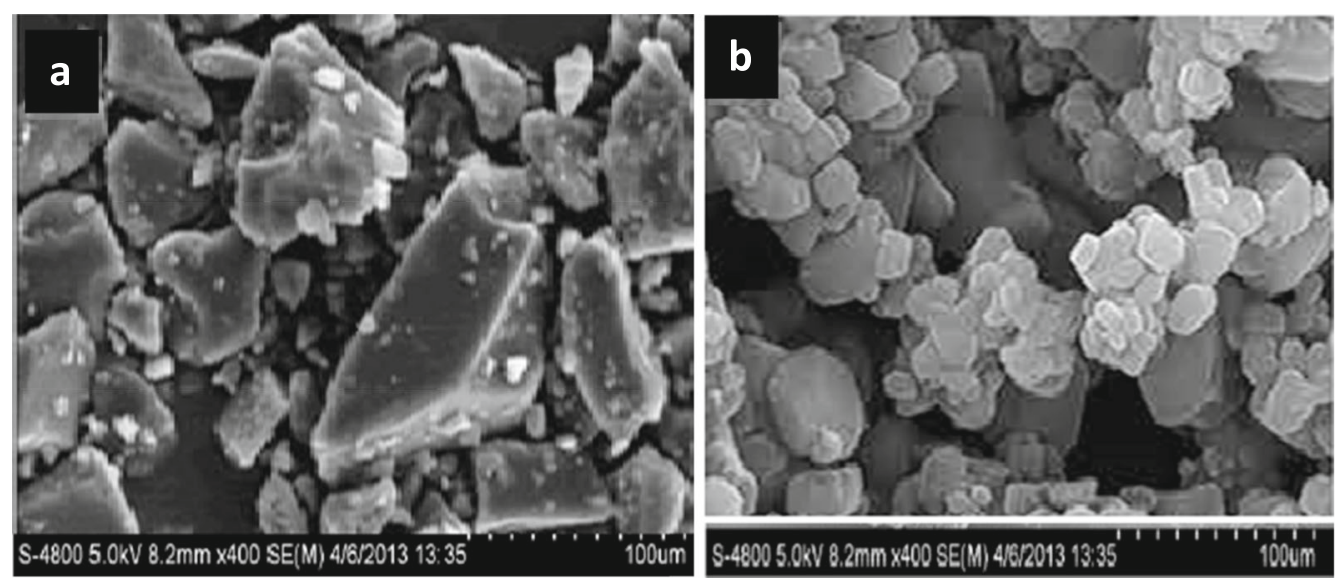

Fig. 7 SEM images of $\mathbf{a}$ pure fenofibrate and $\mathbf{b}$ fenofibrate co-crystal 
and time $\left(X_{2}\right)$. According to equation (6), $X_{1}$ showed predominant positive impact as compared to $\left(X_{2}\right)$ resulting in increased particle size increasing within the $X_{2}$; this might be due to the longer amount of time applied results in the re-bonding between the particles and turning to the agglomeration.

\section{Fourier transform infrared spectroscopy}

The status of the drug with functional groups peak in co-crystal along with new peaks was examined by FTIR. Figure shows (Fig. 5) FT-IR spectra of PEG 4000, pure drug FNO and prepared co-crystals respectively. The changes in IR peaks of FNO in prepared co-crystals compared to pure FNO drug thereby indicating the hetero-molecular interaction, the presence of hydrogen bonding had occurred in the co-crystals. The peak at $2926.45 \mathrm{~cm}-1$ indicated aromatic $\mathrm{C}-\mathrm{H}$ stretching, peak at $1674.87 \mathrm{~cm}-1$ indicated $\mathrm{C}=\mathrm{O}$ stretching whereas, peaks at 1220 and $1033.66 \mathrm{~cm}-1$ indicated aralkyl and dialkyl ether C-O stretching, respectively. In co-crystal spectra there is no peak within range of $2700-3300 \mathrm{~cm}-1$ was observed suggesting the possibility of $\mathrm{O}-\mathrm{H}$ bridging between $\mathrm{C}=\mathrm{O}$ of $\mathrm{FNO}$ and $\mathrm{O}-\mathrm{H}$ of PEG 4000.

\section{Powder X-ray diffraction analysis}

PXRD was a potent technique for the evaluation of the development of an innovative crystal-like phase in a compact state. If an accurate co-crystal has been molded amongst dual solid phases, then spreading pattern of co-crystal would be clearly different after superimposition of every of the compound. In threedimensional arrangement, crystal is periodically settled but amorphous substances have not periodicity and atoms are casually dispersed in three-dimensional space. The point at which $\mathrm{X}$-rays are sprinkles by atom is noted down if the periodic organization found the sprinkling is only specific direction when they knock out the designed lattice planes, the highintensity peaks are formed. Apart from the amorphous phase, the $\mathrm{X}$-rays will be sprinkles in numerous ways prominent to an enormous collision dispersed in a wide array $(2 \Theta)$ as an alternative of great strength narrower peaks. Thus, we can see the large bumpy pattern distributed in a wide range in Fig. 7. Thus, the saturation solubility of co-crystal is higher than that of pure FNO due to its crystalline nature. As we can see, the change in characteristic peaks of cocrystal as compared with pure FNO may be due to the co-former PEG (Fig. 6).

\section{Scanning electron microscope}

In the microphotographs of pure FNO (a), crystal of bigger and regular shape with apparently smooth surface.
Table 5 Micromeritic properties of Fenofibrate Co-crystal (FNOCC7) $(n=3$, mean \pm SD)

\begin{tabular}{ll}
\hline Parameters & Result \\
\hline Angle of Repose $\left(^{(}\right)$ & $21.4 \pm 0.173205$ \\
Carr's Index & $11.8 \pm 0.31$ \\
Hausner Ratio & $1.133 \pm 0.01$ \\
Tap Density & $1.254 \pm 0.05 \mathrm{~g} / \mathrm{ml}$ \\
Bulk Density & $1.106 \pm 0.07 \mathrm{~g} / \mathrm{ml}$ \\
\hline
\end{tabular}

The microphotographs (b) shows prepared cocrystals of FNO, from that it was observed that fenofibrate showed large crystals while cocrystals of co-former showed small, uniform crystals. Cocrystals of FNO reduced crystallinity as compared to pure Fenofibrate (Fig. 7). It was also confirmed by PXRD study.

\section{Micromeritic properties}

The flow properties characterized showed that angle of repose and Carr's index was brought into being to 21.4 and 11.8 respectively which were within the range for good flow of powder (Table 5).

\section{Permeation study}

Standard calibration of FNO was drawn by plotting absorbance v/s concentration using UV-visible spectrophotometer. FNO followed Beer-Lambert's in the concentration series of $10-50 \mu \mathrm{g} / \mathrm{ml}$ at $\lambda_{\max }$ of $263 \mathrm{~nm}$. The calibration curve of FNO was linear $(y=0.0115 x+$ 0.0071 ) with its correlation coefficients being 0.996 . The penetrability of drug applicants over the GI mucosa is a standout amongst the most critical aspects in characterizing their bioavailability and biotic activity. Various in vivo, in situ, and in vitro models are accessible to execute GI absorption of drugs, for example, synthetic membrane, cultured cells, isolated tissues, and body part perfusions. Regularly, these prototypes look for cooperation amongst their amount and prescient perspective.

The plots of the amount of FNO absorbed from the crystal in the intestine (duodenum) at various time intervals. Subsequently executing a linear regression investigation, the slope was taken as the permeation flux $(F$, $\mu \mathrm{g} / \mathrm{min})$. The apparent permeability coefficient $\left(P_{\text {app }} \mathrm{cm} /\right.$ min) was determined according to the Equation (7),

Table 6 Permeation flux and apparent permeability coefficient of FNO and its Co-crystal formulation (FNOCC7) $(n=3$, mean \pm SD)

\begin{tabular}{llll}
\hline Samples & & $F$, flux $(\mu \mathrm{g} / \mathrm{min})$ & $P_{\text {app }} \times 10^{-5}(\mathrm{~cm} / \mathrm{min})$ \\
\hline Intestinal & Pure drug & $0.014 \pm 0.141$ & $3.86 \pm 0.167$ \\
non-everted sac & FNOCC7 & $0.322 \pm 0.068$ & $5.38 \pm 0.093$ \\
\hline
\end{tabular}




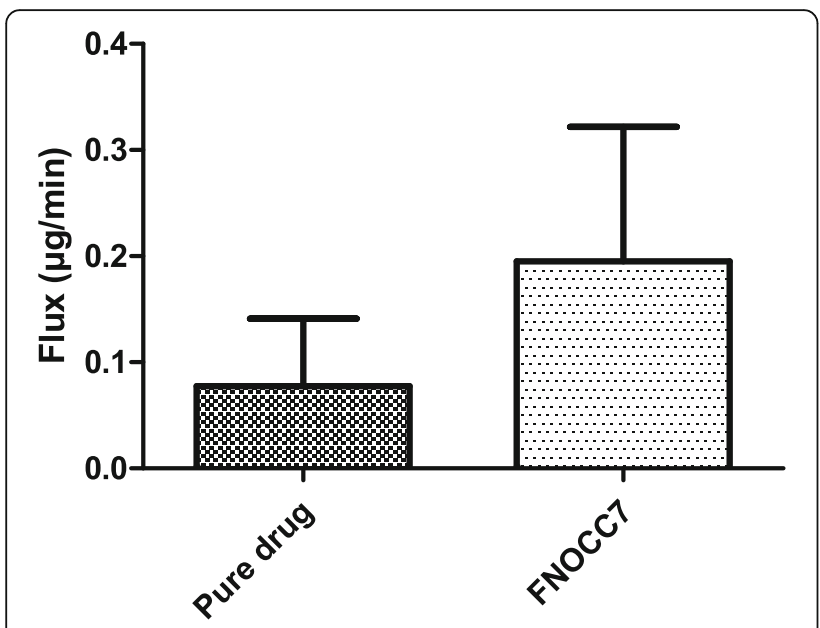

Fig. 8 Permeation flux of fenofibrate pure drug and fenofibrate cocrystal formulation (FNOCC7) in non-everted rat intestinal sac model

$$
P_{\text {app }}=\frac{\mathrm{F}}{\mathrm{SA} \times \mathrm{Co}}
$$

Where, $F$ is flux (slope of linear regression analysis), SA is surface area of intestine $\left(0.75 \mathrm{~cm}^{3}\right), C_{0}$ is an initial concentration of drug $(\mu \mathrm{g} / \mathrm{ml})$.

The rate of permeation (flux, $F$ ) of pure fenofibrate and its co-crystal formulation (FNOCC7) was observed to be $0.014,0.322 \mu \mathrm{g} / \mathrm{min}$, respectively (Table 6). The apparent permeability coefficient $\left(P_{\text {app }}\right)$ of pure FNO and co-crystal was observed to be $3.86 \times 10^{-5}, 5.38 \times$ $10^{-5} \mathrm{~cm} / \mathrm{min}$, respectively (Fig. 8).

\section{Solid unit dosage form}

Based upon the above results of saturation solubility, particle size distribution, permeation flux, and apparent permeability coefficient the FNOCC7 formulation of cocrystal are optimized for further solid dosage form preparation (Table 7). Entire tablets formulated were assessed for the content of active components, hardness, friability, and disintegration time and dissolution rate as per authorized (IP) methods. Monsanto hardness tester was utilized for hardness determination, and Roche friabilator is employed for friability calculations. Lab India tablet disintegration test machine (model DT 1000) was used for disintegration time determination (Table 8).

Table 7 The composition of prepared solid unit dosage form

\begin{tabular}{lll}
\hline S.No & Drug \& Excipients & Composition \\
\hline 1. & Fenofibrate co-crystal & $760 \mathrm{mg}$ \\
& (Equivalent to Fenofibrate 500mg) & \\
2. & Sodium starch glycolate & $75 \mathrm{mg}$ \\
3. & Lactose & $149 \mathrm{mg}$ \\
5. & Polyvinyl pyrrolidone & $75 \mathrm{mg}$ \\
4. & Magnesium stearate & $1 \mathrm{mg}$ \\
\hline
\end{tabular}

Table 8 Evaluation parameters of tablet of Formulation containing co-crystal $(n=3$, mean \pm SD)

\begin{tabular}{llll}
\hline Batch & $\begin{array}{l}\text { Hardness } \\
\left(\mathrm{kg} / \mathrm{cm}^{2}\right)\end{array}$ & $\begin{array}{l}\text { Friability } \\
(\% \text { weight loss) }\end{array}$ & $\begin{array}{l}\text { Disintegration } \\
\text { time }(\mathrm{min})\end{array}$ \\
\hline CCT & $5.12 \pm 0.21$ & $0.58 \pm 0.08$ & $5.40 \pm 1.63$ \\
\hline
\end{tabular}

\section{In vitro dissolution study}

In vitro dissolution outlines of the tablet of Formulation containing co-crystal (CCT) manufactured by wet granulation. In vitro rate of dissolution of CCT enhanced in comparison to the pure drug. The dissolution percentage of FNO pure drug was precise low; with $2.1 \%$ dissolution in $30 \mathrm{~min}$. Dissolution of prepared CCT was significantly enhanced (15.998\% release in $30 \mathrm{~min})$. The drug dissolution of above $69.67 \%$ was obtained in $120 \mathrm{~min}$, and the marketed formulation is $21.61 \%$ release in $120 \mathrm{~min}$ (Table 9). The significant increase in the rate of dissolution accredited to the greater hydrophilic appeal of the co-ordination owing to the existence of water-soluble polymer and that portion of the drug dissolution (Fig. 9).

\section{Stability study}

The formulation containing co-crystal (CCT) were charged on accelerated stability condition $\left(40{ }^{\circ} \mathrm{C}\right.$, $75 \% \mathrm{RH})$ for drug content at 1,2 , and 3 months. The data found shows that there is no significant deviation in appearance, content pure FNO drug and optimized cocrystal up to 3 months (Table 10).

\section{Discussion}

In saturation solubility, the negative distinguished impact of $X_{1}$ and $X_{2}$ indicates that if the number of balls is reduced together with time, enhancement in saturation solubility is observed. This can be supported by the comminution process of the imparting energy, fracture and cleavage of particles occurring when extreme tensions are functional that yield fragments of size 50-80 make the most the size of the preliminary particle size. The positive

Table 9 The drug release profile of Pure FNO, Formulation containing co-crystal (CCT) and Marketed formulation

\begin{tabular}{llll}
\multicolumn{2}{l}{$(n=3$, mean \pm SD $)$} \\
\hline Time & $\begin{array}{l}\text { \% drug release } \\
\text { of Pure drug }\end{array}$ & $\begin{array}{l}\text { \% drug release of Formulation } \\
\text { containing Co-crystal(CCT) }\end{array}$ & $\begin{array}{l}\text { \% drug release } \\
\text { of Marketed }\end{array}$ \\
\hline 0 & 0 & 0 & 0 \\
5 & $0.676 \pm 0.555$ & $0.926 \pm 0.325$ & $2.786 \pm 0.325$ \\
15 & $1.986 \pm 0.642$ & $7.364 \pm 1.024$ & $4.987 \pm 0.554$ \\
30 & $2.109 \pm 0.552$ & $15.998 \pm 1.554$ & $7.988 \pm 0.685$ \\
45 & $2.768 \pm 0.578$ & $23.987 \pm 2.055$ & $10.766 \pm 0.885$ \\
60 & $3.654 \pm 0.702$ & $32.986 \pm 3.688$ & $14.559 \pm 1.525$ \\
120 & $10.39 \pm 0.924$ & $69.67 \pm 5.326$ & $21.618 \pm 3.544$ \\
\hline
\end{tabular}




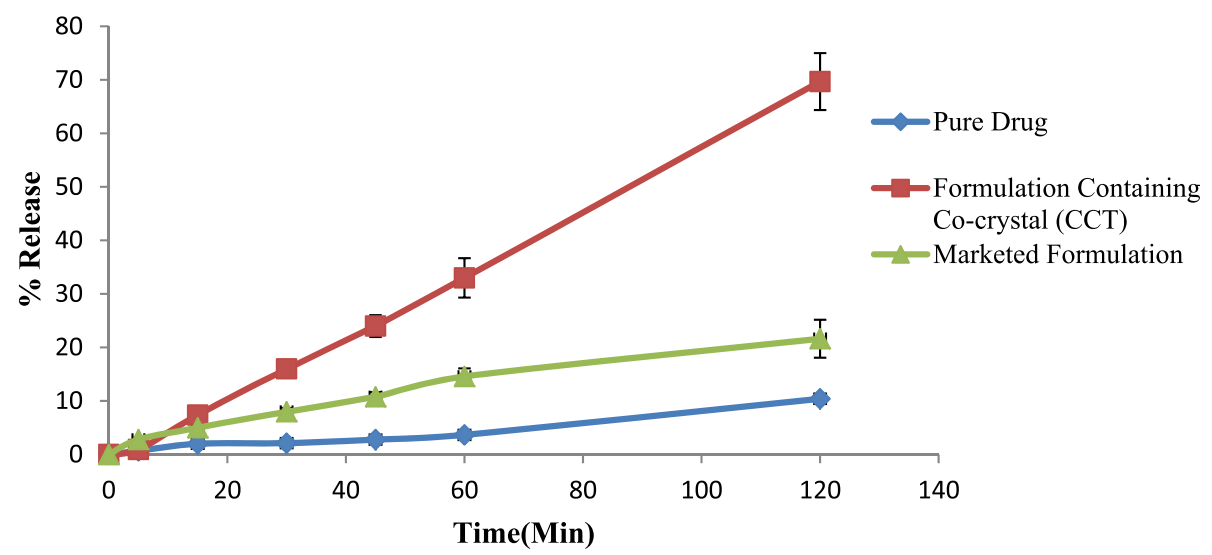

Fig. 9 Dissolution profile of pure drug (blue line), formulation containing co-crystal (CCT) (red line) and marketed formulation (green line) ( $n=3$, mean \pm SD)

value (0.084) of the interaction term $X_{1} X_{2}$ attributes to slight decrease within the saturation solubility. This may be because of low attrition and impaction mechanism of the colliding balls that disrupts their binding force as in $\left(X_{2}\right)$. The rise in a number of balls consequence in a reduction in saturation solubility as an outcome of increasing the number of balls occupies over $50 \%$ of the interior volume of the mill leading to fewer voids.

The curvilinear graph explains the increase within the particle size with an increase within the number of balls as shown in $X_{1}$ whereas, $\mathrm{X}_{2}$ shows the relatively opposite relationship as mirrored in equation (6). At the initial time, particle size determined was low because the particles might have occupied $50 \%$ of the volume of mill resulting in high friction between the particles however because of increase is the time alongside along with of balls the particle size was found to be increased. The rise in particle size can be owing to excessive aggregation of particles carried out because of the increase within the number of balls. However, the pronounced positive signs of constant b0 could also be because of less contact with the physical mixture throughout the fragmentation method and resulting in the coarser particle size in the incidence of each the method parameters.

Non-everted rat GI sac demonstrates a broadly utilized procedure to anticipate in vivo human absorption kinetics and bioavailability of combinations with reduced water dissolvability, poor stability and could give data almost

Table 10 Stability study of Formulation tablet contained Co-crystals ( $n=3$, mean \pm SD)

\begin{tabular}{lllll}
\hline Parameters & \multicolumn{4}{l}{ Accelerated condition $\left(40^{\circ} \mathrm{C}, 75 \% \mathrm{RH}\right)$} \\
\cline { 2 - 5 } & \multicolumn{4}{l}{ Formulation containing co-crystal $(\mathrm{CCT})$} \\
\hline Sampling Intervals & Initial & 1 month & 2 month & 3 month \\
\%Drug content & $98.41 \pm 0.19$ & $97.78 \pm 0.41$ & $96.89 \pm 0.22$ & $96.81 \pm 0.71$ \\
\hline
\end{tabular}

drug absorption mechanism. The situation favorable circumstances above the everted sac show are the straightforward arrangement, necessities a smaller amount of test sample, permits the progressive accumulation of serosal tests with not as much of GIT morphological variations. Hence, this strategy was utilized to evaluate the absorption of FNO in rat stomach as well as intestine with the end goal to discover the site-subordinate ingestion of FNO beginning the rat abdominal region. The rate of permeation (flux, $F$ ) of pure fenofibrate and its co-crystal formulation (FNOCC7) was observed to be $0.014,0.322 \mu \mathrm{g} / \mathrm{min}$, respectively. The apparent permeability coefficient $\left(P_{\text {app }}\right)$ of pure FNO and co-crystal was observed to be $3.86 \times 10^{-5}$, $5.38 \times 10^{-5} \mathrm{~cm} / \mathrm{min}$, respectively.

The enhanced rate of dissolution of formulated CCT can be accredited to a rise in the superficial extent of FNO subsequently adsorption onto the drug and polymer in the case of Co-crystal comprising Polyethylene glycol, as the meltable binder the dissolution rate, was enhanced as related to the pure drug.

\section{Conclusions}

The solubility and dissolution percentage of FNO can be improved by the utilization of co-crystal of FNO with PEG 4000. The solubilization impact of PEG 4000 might be contributed because of decrease of molecule conglomeration of the presence of the drug crystallinity, expanded wettability, and dispersibility; pharmaceutical cocrystals speak to a beneficial class of crystal form with regard of pharmaceuticals. Co-crystals of drugs and drug aspirants speak to another kind of material for pharmaceutical development. Co-crystals are moderately new to the pharmaceutical industry, and pharmaceutical co-crystals have given another course to manage issues of inadequately with problems of poorly soluble drugs. Co-crystals can possibly be significantly more helpful in pharmaceutical substances 
than solvates or hydrates. The importance of cocrystals in API definition incorporates the capacity to adjust physical properties, characterization of API, distinguish and grow novel, exclusive systems of recommended drugs and the coincidental to produce protected innovation.

\section{Abbreviations}

BCS: Bio-pharmaceutics classification system; BD: Bulk density;

CCT: Formulation containing co-crystal.; CPCSEA: Committee for Purpose of Control and Supervision of Experiments on Animals; FNO: Fenofibrate; FNOCC7: Fenofibrate containing co-crystal formulation; FT-IR: Fourier transform infrared spectroscopy; ICH: International Conference on Harmonization; $P_{\text {app: }}$ Permeability coefficient; PEG 4000: Polyethylene glycol 4000; PVP: Polyvinyl pyrrolidone; PXRD: Powder X-ray diffraction; RPM: Rotation per minute; SEM: Scanning electron microscopy; SLN: Solid lipid nanoparticles; TD: Tapped density; USP: United State Pharmacopoeia

\section{Acknowledgements}

The authors express special thanks to Ashwin Kuchekar (Department of Pharmaceutics, Poona College of pharmacy, BVDU, Pune) for his kind support and Priya Mishra (Department of Pharmacology, GGV, Bilaspur) for animal experimentation knowledge.

\section{Authors' contributions}

SR designed the study and developed the methodology. RJ performed the experiments. WA wrote the manuscript. NG contributed to manuscript revision and provided supervision. All authors reviewed and edited the manuscript. All authors read and approved the final manuscript.

\section{Funding}

This research did not receive any specific grant from funding agencies in the public, commercial, or not-for-profit sectors.

\section{Availability of data and materials}

The datasets generated during and/or analyzed during the current study are available from the corresponding author on reasonable request.

\section{Ethics approval and consent to participate}

The ex vivo intestinal permeation study work was completed at Guru Ghasidas Vishwavidyalaya, according to the protocols permitted by the Committee for Purpose of Control and Supervision of Experiments on Animals (CPCSEA), Ministry of Social Justice and Empowerment, Government of India, under the reference no. 73/IAEC/Pharmacy/2014 on the recommendations of the Institutional Animal Ethical Committee of Guru Ghasidas Vishwavidyalaya (Bilaspur, India).

\section{Consent for publication}

Not applicable

\section{Competing interests}

The authors declare that they have no conflict of interests.

\section{Author details}

${ }^{1}$ School of Studies in Pharmaceutical Sciences, Jiwaji University, Gwalior (M.P)-474011, India. ${ }^{2}$ Poona College of Pharmacy, Bharati Vidyapeeth University, Pune 411038 , India.

Received: 2 August 2019 Accepted: 9 October 2019

Published online: 30 December 2019

\section{References}

1. Martindale (1989) Fenofibrate. The extra pharmacopeia $29^{\text {th }}$, Pharmaceutical Press, London.

2. Munoz A, Guichard JP, Reginault PH (1994) Micronised fenofibrate. Atherosclerosis 110:S45-S48

3. Adkins JC, Faulds D (1997) Micronised fenofibrate. Drugs 54(4):615-633

4. Mahanty S, Sruti J, Patra CN, Rao MB (2010) Particle design of drugs by spherical crystallization techniques. Int J Pharm Sci Nanotech 3(2):912-918

5. Sekhon BS (2009) Pharmaceutical co-crystals-a review. ARS Pharm 50:99-117
6. Kaur L, Kumar S (2011) Solid dispersions: a promising approach for improving dissolution characteristics of a poorly soluble drug. Int I Pharm Res 3:1-7

7. Zaheer A, Naveen M, Santosh MK, Imran K (2011) Solubility enhancement of poorly water soluble drugs: A review. Int J Pharm Technol 3:807-823

8. Oktabec Z, Kos J, Mandelova Z, Havelkova L, Pekarek T, Rezacova A, Jampílek J (2010) Preparation and properties of new co-crystals of ibandronate with gluco-or galactopyranoside derivatives. Molecules 15(12): 8973-8987

9. Vogt M, Kunath K, Dressman JB (2008) Dissolution improvement of four poorly water soluble drugs by cogrinding with commonly used excipients. Eur J Pharm Biopharm 68(2):330-337

10. Jamzad S, Fassihi R (2006) Role of surfactant and pH on dissolution properties of fenofibrate and glipizide-a technical note. Aaps Pharmscitech 7(2):E17-E22

11. Hanafy A, Spahn-Langguth H, Vergnault G, Grenier P, Tubic Grozdanis M, Lenhardt T (2007) Pharmacokinetic evaluation of oral fenofibrate nanosuspensions and SLN in comparison to conventional suspensions of micronized drug. Adv Drug Deliv Rev 59:419-426

12. Savjani KT, Gajjar AK, Savjani JK (2012) Drug solubility: importance and enhancement techniques. ISRN Pharm 5:1-10

13. Kausalya J, Suresh K, Padmapriya S, Rupenagunta A, Senthilnathan B (2011) Solubility and dissolution enhancement profile of telmisartan using various techniques. Int J Pharm Tech Res 3(3):1737-1749

14. Mahapatra AK, Murthy PN, Biswal S, Mahapatra AP, Pradhan SP (2011) Dissolution enhancement and physicochemical characterization of valsartan in solid sispersions with $\beta-C D, H P \beta-C D$, and PVP K-30. Dissol Technol 18:39-45

15. Sharma P, Kapoor A, Bhargava S (2012) A review on: Solubility enhancement by implementing solid dispersion technique for poorly water soluble drug. Res J Pharm Bio Chem Sci 3(1):847-859

16. Blagden N, de Matas M, Gavan PT, York P (2007) Crystal engineering of active pharmaceutical ingredients to improve solubility and dissolution rates. Adv Drug Deli Rev 59(7):617-630

17. Cooper J, Gunn C (1986) Powder flow and compaction. CBS Publishers and Distributors, New Delhi

18. United States Pharmacopeia 24/NF19 (2000) The Official Compendia of Standards. United States Pharmacopoeia Convention Inc.

19. Ruan LP, Chen S, Yu BY, Zhu DN, Cordell GA, Qiu SX (2006) Prediction of human absorption of natural compounds by the non-everted rat intestinal sac model. Eur J Medi Chem 41(5):605-610

20. Banker GS, Anderson NRI (1987) The Theory and Practice of Industrial Pharmacy. Varghese Publishing House, Mumbai.

\section{Publisher's Note}

Springer Nature remains neutral with regard to jurisdictional claims in published maps and institutional affiliations.

\section{Submit your manuscript to a SpringerOpen ${ }^{\circ}$ journal and benefit from:}

- Convenient online submission

- Rigorous peer review

- Open access: articles freely available online

High visibility within the field

- Retaining the copyright to your article

Submit your next manuscript at $\boldsymbol{\nabla}$ springeropen.com 